\title{
Using Concept Mapping to Develop a Logic Model and Articulate a Program Theory: A Case Example
}

\author{
SVETLANA YAMPOLSKAYA, TERESA M. NESMAN, MARIO \\ HERNANDEZ, AND DIANE KOCH
}

\begin{abstract}
Using a case example of one of the mental health agencies in Florida, we demonstrate the utility of concept mapping for developing a program logic model and articulating a program theory for program assessment. The results of the concept mapping procedure enabled identification of 100 program services as described in statements by staff. Moreover, results revealed four major categories of those services and the main strategies used. This information was used to develop the first three components of a logic model. Concept maps were also used to reveal underlying assumptions built into the agency's theoretical approach.
\end{abstract}

\section{INTRODUCTION}

During the last decade, many public and non-profit providers of children's mental health services have been pressed toward accountability by funding agencies (Hernandez, 2000; Hodges \& Hernandez, 1999; Savas, Fleming, \& Bolig, 1998). Increasingly, service providers face requests from legislators and government officials for data that provide evidence of service efficacy (Beck, Meadowcroft, Mason, \& Kiely, 1998). Providers are often being required to document specific interventions and expected outcomes and to demonstrate their efforts to increase program effectiveness. As a result, a great number of providers need to identify services or policies that are designed to lead to positive changes in the children and families they serve. Administrators and service providers are searching more than ever for ways to describe the service models and philosophies of their programs in order to demonstrate how they expect to facilitate change (Pumariega, 1996). As Stinchcomb (2001) noted, if the mission

Svetlana Yampolskaya - The Department of Child and Family Studies, Louis de la Parte Florida Mental Health Institute, 13301 Bruce B. Downs Blvd., Tampa, FL 33612, USA; Tel: (1) 813-974-8218; E-mail: yampol@ mirage.fmhi.usf.edu.

American Journal of Evaluation, Vol. 25, No. 2, 2004, pp. 191-207. All rights of reproduction in any form reserved. ISSN: $1098-2140$ (C) 2004 by American Evaluation Association. Published by Elsevier Inc. All rights reserved. 
is not well articulated and the pathway to achieving it not clearly outlined, it is impossible to determine why the program produced certain outcomes or why the outcomes were not achieved. Accountability is unattainable without clear specification of how the program's activities or intervention are expected to achieve the program goals (Solomon, 2002).

To better understand the relationships among program inputs and outcomes, and also to reveal the mechanisms of change involved in moving from inputs to desired results, several researchers have suggested the use of logic models (Bickman, Heflinger, Pion, \& Behar, 1992; Julian, 1997; McLaughlin \& Jordan, 1999; Weiss, 1997). Developing a logic model helps to articulate a theory of change that is a plausible and logical explanation of how a program aims to produce changes (Hernandez, Hodges, \& Cascardi, 1998; McLaughlin \& Jordan, 1999). Following a logical sequence, it clarifies how the program goals, individual components, and specific activities actually fit together and how they are likely to produce the desired outcomes (Chen \& Rossi, 1983; Hernandez, 2000; Rossi \& Freeman, 1993). Logic models can help one to understand what actually happened in a specific program. They also are important tools for identifying essential components of a program for replication (Pumariega, 1996). Finally, logic models provide the information about the program components needed to examine program fidelity (i.e., the congruence between what was intended and what was actually done), which ultimately is linked to program effectiveness (Friedman, 1997; Mowbray, Holter, Teague, \& Bybee, 2003). As Chen (1990) has noted, a logic model can help compare how a program should operate to its actual operation.

One way to articulate or extract a theory of change is to use the elicitation methodology, that is, to construct "mental models" or "cognitive maps" of program developers and stakeholders (Leeuw, 2003). As Leeuw noted, managers, stakeholders, and program staff have "mental maps" about their organization, and these maps partly determine their behavior. Therefore, these maps are crucial to explaining organizational outcomes. One of the variant of the elicitation method is Trochim's (1989b) approach to concept mapping. In this case "theories in use" (Leeuw) can be detected by using trigger questions (e.g., focus statements). Responses to focus statements or participants' perceptions of program services are used to understand how client change is thought to be achieved (Unrau, 2001).

The concept mapping technique is useful not only for explicating program theories but also for identifying the key elements of a program and portraying their relationships to one another (Shern, Trochim, \& LaComb, 1995). As such, concept mapping may also be quite helpful in developing parts of a logic model. In this study, concept mapping was used both to facilitate the modeling process and to articulate the theory of change. The purpose of this paper, therefore, is to demonstrate the use of concept mapping for logic model development and articulation of a theory of change and to discuss implications of this methodology in assessing children's mental health services. The case example of the Florida Integrated Team Program (FITP) ${ }^{1}$ is used.

\section{About the Agency}

The Florida Integrated Team Program is a small, nonprofit, community-based agency that provides mental health services for children with multiple needs. Children are referred by school psychologists or other mental health specialists, or they are brought by parents without referrals. The program is implemented by a multidisciplinary team of professionals and designed to provide multidisciplinary assessments, diagnostic evaluations, and intervention recommendations for children who may need to receive special educational services in Florida. The program is innovative, using a strength-based, holistic approach that integrates 
educational, psychological, health, language, and other information affecting the child and family. The agency promotes the use of complex interventions and has become a national role model for fully integrated family-centered care. To assure sustainability and accountability, the program staff requested assistance in conducting a program assessment. The specific goals of the assessment were to help the program staff articulate the program theory of change and to identify outcomes that might be measured in the future program evaluation.

\section{METHOD}

\section{Participants}

The participants were seven staff members and coordinators from the Florida Integrated Team Program (FITP) who represent multiple disciplines, including a developmental pediatrician, a child psychiatrist, a clinical social worker, a psychologist, a speech and language pathologist, an education specialist, and a family consultant. All FITP staff was directly involved in providing services at the agency and all were familiar with children's mental health issues. All participants $(n=7)$ took part in the mapping process (brainstorming, sorting, and rating) and in a face-to-face discussion to interpret the results of the concept mapping and develop the logic model.

\section{Procedure}

Data were collected via a concept mapping procedure (Trochim, 1989a) and semi-structured interviews. Interviews were conducted with the program staff and served to clarify the purpose of the program, its target population, its resources, and its expected outcomes, as well as further planning and evaluation goals. In addition, a discussion session was held with the program staff to interpret the results of the concept mapping and to develop a logic model.

The concept mapping procedure with the FITP staff was accomplished in two sessions. During the first session, in which structured brainstorming was conducted, participants were given the following focus statement: "Generate statements (short phrases or sentences) that describe the specific elements of all services that this team provides." The focus statement was used to elicit statements guided by predetermined criteria. As a result of the brainstorming session, 103 statements were generated. Three statements were later removed from the analysis as repetitive. During the second session, statements were placed on cards and participants sorted them into piles based on similarity. The sorting procedure contained three restrictions: (a) the participants could not put all the statements in one pile, (b) the participants could not make as many piles as the number of statements, and (c) the participants could not put a statement into more than one pile. After sorting the statements into piles, the team members rated specific activities on how important and how effective they were. The importance was measured by a 5-point Likert-type response scale, where $1=$ relatively unimportant, $2=$ somewhat important, $3=$ moderately important, $4=$ important, and $5=$ very important. Similarly, the effectiveness was measured by a 5-point Likert-type response scale, where $1=$ not effective, $2=$ a little effective, $3=$ somewhat effective, $4=$ effective, and $5=$ very effective.

The results of concept mapping and data obtained from interviews and information from discussion sessions with the FITP staff were used to help create the logic model of FITP. The creation of the program logic model was a three-stage process that involved participation of 
both the FITP staff and the evaluators. The first step consisted of the evaluators filling out a logic model diagram based on a three-part model developed by Hernandez and Hodges (2001). Various maps (i.e., point maps, different cluster maps) and statements constituting the map were reviewed in order to arrive at the model. Second, the initial model was shown to the FITP staff, and the key aspects of the program as well as intended program outcomes were discussed. Concept maps were presented and used as tools for the logic model development process. Specifically, the point map, the ten-cluster, and four-cluster solution maps were reviewed and discussed by the FITP team and the researchers in order to identify services delivered, strategies used, and major program components (these maps are illustrated below). The team members were asked to examine the statements they had generated and the clusters obtained from the concept mapping and to check these against related sections in the logic model diagram. The team members generally agreed that the model was accurate and that the program worked as depicted. They suggested only minor modifications regarding the "conditions" and short-term outcomes. The logic model also was examined in order to establish the linkages between the core elements of the program (i.e., target population, services, strategies, and expected outcomes) and to specify the theory of change. In the final stage the logic model was refined by the evaluators based on team members' revisions and sent to them for the final confirmation.

\section{Analytical Approach}

The data analyses included: (a) concept mapping (Trochim, 1993), (b) the ALSCAL multidimensional similarity scaling model (Carroll \& Chang, 1970; Kruskal \& Wish, 1978) available in the SPSS package (version 11.0), and (c) hierarchical cluster analysis using SPSS with the method devised by Ward (1963). The data were analyzed using ALSCAL (i.e., multidimensional scaling) in order to obtain a greater than two-dimensional solution if applicable. Hierarchical cluster analysis was conducted using SPSS in order to obtain the squared Euclidean distance coefficients for different cluster solutions.

\section{RESULTS}

\section{Logic Model and Expected Outcomes}

Figure 1 displays the logic model developed for the FITP program. This logic model is based on five components. The first component (the first column) describes the target population (i.e., children with multiple needs) and conditions (conflict between child and environment) that the program hopes to ameliorate (Hernandez, 2000). The second component (the second and the third columns) describes the specific services identified by the staff and the main categories of services. The third component (the middle of the diagram) describes the main strategies used by the program staff, and finally, the fourth and fifth components identify expected short-term and long-term outcomes. According to Hernandez (2000), these components are essential in building a "theory of change." The information for the first three components of the logic model was primarily obtained from concept mapping. The last two components of the logic model were developed based on information from the interviews and the discussion session with the program staff. The "target population and condition" column was completed first. The content of the logic model components is described below. 


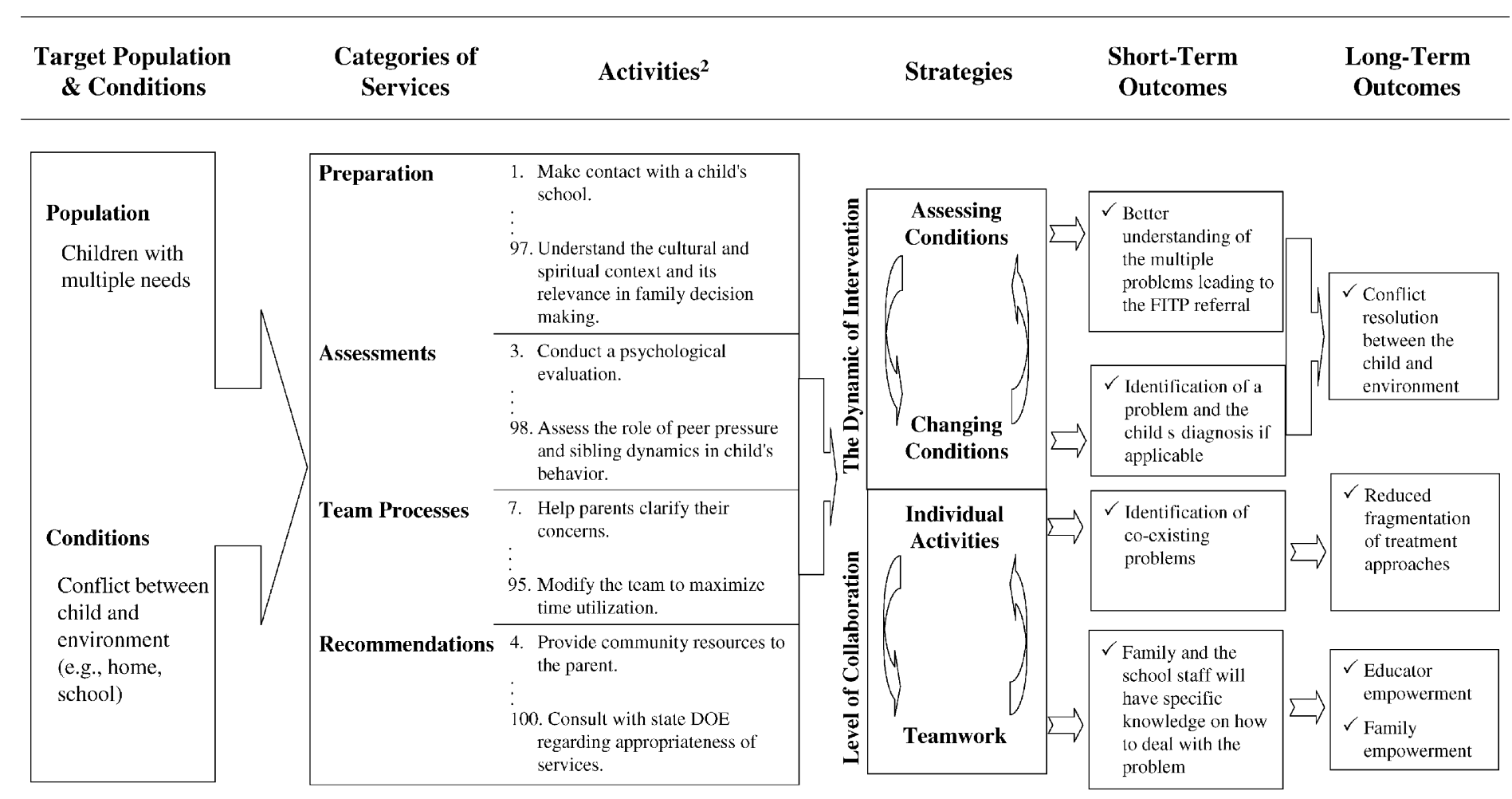

Figure 1. Logic model for the Florida Integrated Team Program. 
Target population and conditions. The statements from the concept mapping described the FITP target population as children with complex issues that cross multiple disciplines. For example, a number of statements indicated that the agency provides a highly complex child assessment process (e.g., "Evaluate the child's developmental level," "Assess the child's communication skills," "Conduct a psychiatric evaluation"). The statements also identified the family as part of the FITP target population (e.g., "Evaluate the family's developmental level," "Provide a play environment to evaluate the family interaction").

During the session when the logic model was discussed, program staff confirmed that children with multiple needs are the target population. These children are typically seen as "complex," have multiple diagnoses, and require services from professionals in different disciplines. The participants also indicated that the FITP targets the child's social environment, such as interactions with family and educators, and that their goal is to address the conflict between the child and the child's social environment.

Services provided. The program components and associated services were described next. Each service provided by FITP, as described in the statement by program staff, was shown on a point map generated by the concept mapping (see Fig. 2). The distance between points (i.e., statements that describe elements of services) reflects the degree of similarity between them, with a smaller distances corresponding to more similarity and larger distances corresponding to less similarity (Rosenberg, Nelson, \& Vivekananthan, 1968). The point map represents the two-dimensional solution of the MDS analysis ${ }^{2}$ and had a final stress value of .269. The map was analyzed to determine the scope of services and types of services provided. The 100 statements that describe services provided by the agency are shown in Table 1. Examination of specific statements found that the program included multidimensional, multidisciplinary, and

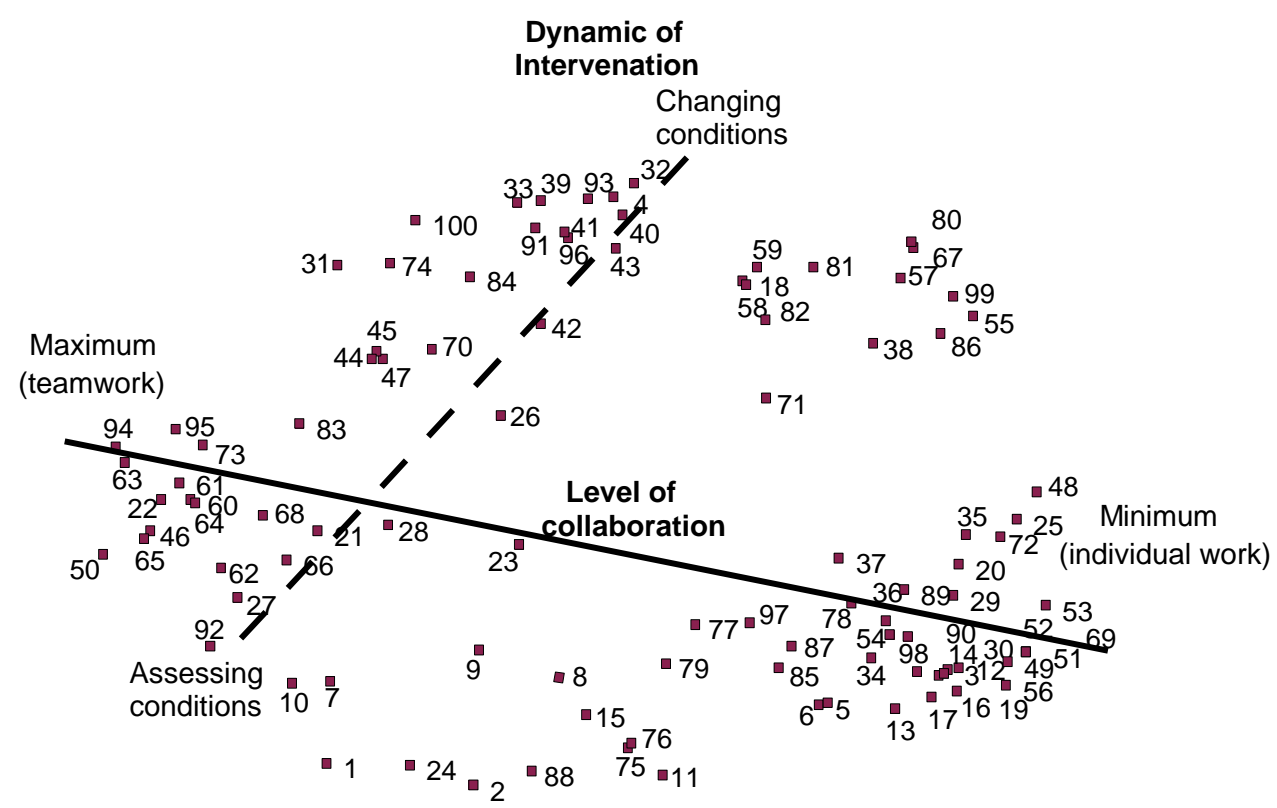

Figure 2. Point map with statement numbers as a result of concept mapping analysis. 
TABLE 1.

Program Activities as Described in Statements by the Staff

\begin{tabular}{ll}
\hline Statement \# & Cluster \\
\hline & Preparation \\
1 & Make contact with a child's school. \\
2 & Interview the child's teacher. \\
5 & Review and clarify the history and records obtained from parents. \\
6 & Obtain history from the child. \\
8 & Prepare parents for the clinic orientation. \\
9 & Clarify the parents' expectations for this evaluation. \\
11 & Interview the family for the purpose of identifying their concerns. \\
15 & Clarify the student's expectations for the evaluation. \\
24 & Collect information from multiple providers in the community. \\
75 & Observe the child in the classroom environment. \\
76 & Observe the context of the classroom. \\
77 & Understand family relationships. \\
79 & Understand the modifications made in the classroom. \\
85 & Review IEP. \\
87 & Understand how the child works and learns. \\
88 & Consultation with classroom teacher and school personnel regarding how child \\
97 & functions in school setting.
\end{tabular}

\section{Assessment}

Conduct a psychological evaluation.

Evaluate the child's developmental level.

Evaluate the family's developmental level.

Assess the child's communication skills.

Provide a play environment to evaluate the child.

Provide a play environment to evaluate the family interaction.

Conduct a psychiatric evaluation.

Provide a psychiatric diagnosis if applicable.

To understand a child's behavior in the context of his/her family and school/community.

Provide integration of historical elements to arrive at etiology of their issues.

Provide a speech and language assessment.

Determine the student's functional educational level.

Provide an understanding of the child's perspective.

Assessing child and family strengths.

Assessing strengths of the education environment.

Acknowledge that emotional functioning plays a central part in all of development.

Look at environmental variables: physical.

Measure growth and physical attributes and motor functions.

Assess their nutritional diet.

Assess medical compliance.

Review medication history and current status/role that the medication plays.

Conduct evaluation without medication if medically safe.

Provide neurological examinations when requested.

Stretch people's mindset with regards to conceptualization of the child. 
TABLE 1.

(Continued)

\begin{tabular}{|c|c|}
\hline Statement \# & Cluster \\
\hline 78 & Understand the modifications families have made in the home. \\
\hline 89 & Integrate previous and current test results. \\
\hline 92 & $\begin{array}{l}\text { Determine emotional impact child has had on his/her home and school environment } \\
\text { and vice versa. }\end{array}$ \\
\hline \multirow[t]{2}{*}{98} & Assess the role of peer pressure and sibling dynamics in child's behavior. \\
\hline & Team Process \\
\hline 7 & Help parents clarify their concerns. \\
\hline 10 & Clarify the educator's expectations. \\
\hline 21 & $\begin{array}{l}\text { Provide an opportunity for the family to participate actively in the evaluation } \\
\text { process. }\end{array}$ \\
\hline 22 & Provide an opportunity for multiple disciplines to come together in a meeting. \\
\hline 23 & $\begin{array}{l}\text { Provide an opportunity for multiple informants to contribute to the evaluation } \\
\text { process, which would include providing history, performing evaluation, providing } \\
\text { impressions and recommendations. }\end{array}$ \\
\hline 26 & To be certain that the parents' concerns are addressed. \\
\hline 27 & To be certain that the educators' concerns are addressed. \\
\hline 28 & To be certain the child's concerns are addressed. \\
\hline 46 & Provide a model of team support and communication. \\
\hline 50 & Provide a holistic approach. \\
\hline 60 & Involve family members in team discussions. \\
\hline 61 & Involve educators and providers in team discussions. \\
\hline 62 & Provide an opportunity for team members to share their impressions. \\
\hline 63 & Provide an opportunity for teamwork in progress. \\
\hline 64 & Provide all team members an opportunity to hear how others think. \\
\hline 65 & $\begin{array}{l}\text { Provide team members an opportunity to observe and participate in the consultation } \\
\text { group. }\end{array}$ \\
\hline 66 & Define the consultation team as relevant disciplines, family and educators. \\
\hline 68 & Provide encouragement and reassurance to allay anxieties and fears of family. \\
\hline 73 & Provide for dialogue between parents and teachers. \\
\hline 83 & Make people feel safe, welcome and respected when come to FDLRS. \\
\hline 92 & Understand and accept each family's individuality. \\
\hline 94 & Modify the team as necessary to be more responsive to family and educator's needs. \\
\hline \multirow[t]{2}{*}{95} & Modify the team to maximize time utilization. \\
\hline & Recommendations \\
\hline 4 & Provide community resources to the parent. \\
\hline 18 & Assist the educators in understanding the child's needs better. \\
\hline 31 & Provide a link with referring agent. \\
\hline 32 & Provide resources for the referring agent. \\
\hline 33 & Maintain a good relationship with referring agent. \\
\hline 38 & Providing documentation of the assessment. \\
\hline 39 & $\begin{array}{l}\text { Providing names and numbers of contact people to facilitate ongoing } \\
\text { communication with the FDLRS team. }\end{array}$ \\
\hline 40 & Provide ongoing consultation with educators and parents. \\
\hline 41 & Provide outreach for educators unable to attend meeting. \\
\hline 42 & Empower families. \\
\hline
\end{tabular}


TABLE 1.

(Continued)

\begin{tabular}{ll}
\hline Statement \# & \multicolumn{1}{c}{ Cluster } \\
\hline 43 & Empower educators. \\
44 & Lend emotional support to parents. \\
45 & Lend emotional support to students. \\
47 & Lend emotional support to extended family. \\
55 & Make recommendations for changes in medication status if indicated. \\
57 & Help define goals for optimizing child's potential. \\
58 & Recommend learning environment appropriate to the child's developmental level. \\
59 & Educate the family about particular diagnoses. \\
67 & Provide advice giving for certain aspects of behavior management. \\
70 & Provide encouragement and reassurance to educators. \\
71 & Reframe referral concerns and give a new twist to make specific sense. \\
74 & Communication with community providers already involved with the child, if \\
& requested by family members. \\
80 & Give ideas about what the family can do differently. \\
81 & Give ideas about what the school can do differently. \\
82 & Support successful interventions. \\
84 & Attempt to understand local school and state regulations regarding classroom \\
& placement. \\
86 & Determine appropriateness of IEP based on team's conclusions and child's progress \\
91 & and needs. \\
93 & Ask for feedback from parents, educators and referring agents regarding team's \\
93 & evaluation. \\
96 & Let team know about feedback from parents, educators and referring agents. \\
& Consultation with regional FDLRS centers to determine appropriate resources, \\
& materials and services in their districts. \\
& Assist the family in planning for the future. \\
& Consult with state DOE regarding appropriateness of services. \\
\hline
\end{tabular}

multifaceted interventions that targeted children with multiple needs and diverse conditions that require change. The point map not only revealed existing services but also suggested a gap in service provision. When the participants examined the point map they agreed that their program needed to ensure that the effects of their treatment efforts were sustained. Therefore, the program needed follow-up to ensure that recommendations from staff could be carried out and effective.

Main categories of services. To identify categories of services provided by FITP staff and the structure of these services, a cluster map was analyzed. An important step when performing cluster analysis is choosing the number of categories (clusters) that best describes the sample (Lambert, Brannan, Breda, Heflinger, \& Bickman, 1998). In order to accomplish this task, the values of a coefficient that represents the squared Euclidean distance between two points at each stage of the cluster formation in the agglomeration schedule were examined. The squared Euclidean distance coefficient for a four-cluster solution was equal to 9623.5, which was followed by a fairly large increase in the value of the distance measure (to 11456.8) when the three-cluster solution was obtained. Because it was the first observed jump in the 


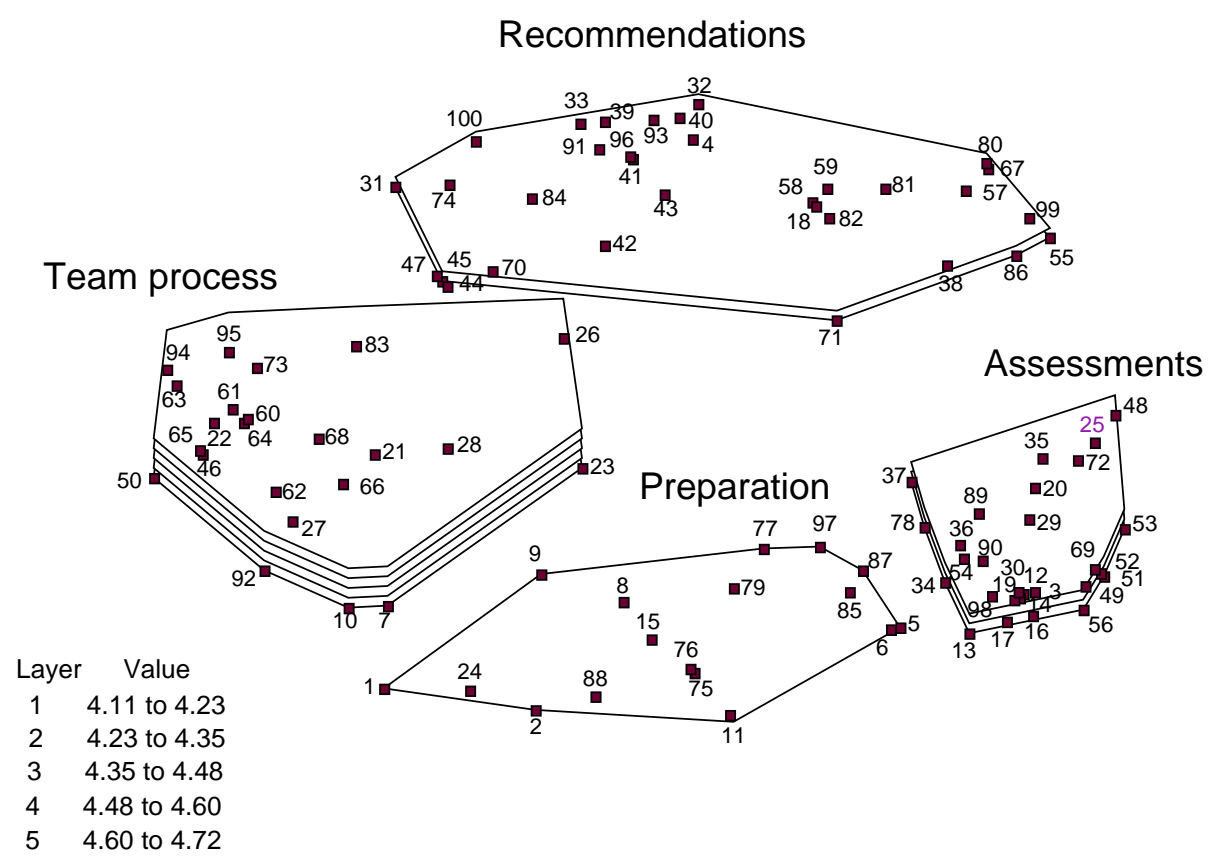

Figure 3. Four-cluster solution rating map. The perceived importance of service activities.

value of the distance measure, the four-cluster solution was chosen. In addition, when different cluster solutions were presented to the FITP staff, it appeared that the four-cluster solution had a practical value, was easily interpretable, and made sense to the participants. Four categories of services were identified by four clusters (see Fig. 3): (a) preparation, (b) assessments, (c) team process, and (d) recommendations. These clusters reflect the program process, which begins with all preparatory activities (e.g., gathering a child's records, obtaining necessary information), followed by the activities that deal with child/family assessment (e.g., conducting psychological evaluation, evaluating a child's and family's developmental levels). The process continues with all activities that require the participation of other parties and a higher level of collaboration (e.g., involving family members in team discussions, assisting educators, providing links with referring agencies), and finishes with the activities that aim to increase parents' and educators' knowledge that ultimately helps them to deal with problems (e.g., suggesting what families can do differently, suggesting what the school can do differently, providing community resources to parents).

Strategies used by FITP. The third column of the logic model (see Fig. 1) was completed by examining the point map and providing dimensional interpretation. The examination of the two-dimensional solution point map suggested two interpretable dimensions of the service elements configuration: the level of collaboration and the dynamic of intervention. The dynamic of intervention dimension can be seen progressing from the lower-left corner to the upper-middle area of the map (see Fig. 2). This continuum represents activities ranging from understanding and assessing conditions such as understand and accept each family's individuality (statement 92), be certain that the educators' concerns are ad- 
dressed (statement 27), be certain the child's concerns are addressed (statement 28), and define the consultation team as relevant disciplines, family and educators (statement 66), to activities that consist of changing those conditions, such as provide resources for the referring agent (statement 32), provide community resources to the parent (statement 4), provide ongoing consultation with educators and parents (statement 40), and providing names and numbers of contact people to facilitate ongoing communication with FITP team (statement 39).

The second dimension identified on the point map was the level of collaboration. This dimension forms a continuum from the lower-right corner of the map. The activities in this corner appear to require minimum collaboration (individual activities), such as provide neurological examination when requested (statement 69), measure growth and physical attributes and motor functions (statement 51), assess their nutritional diet (statement 52), and look at environmental variables: physical (statement 49). Activities in the left side of the map appear to require a high level of collaboration, such as, provide an opportunity for teamwork in progress (statement 63), modify the team to maximize time utilization (statement 95), involve family members in team discussions (statement 60), involve educators and providers in team discussions (statement 61), and provide team members an opportunity to observe and participate in the consultation (statement 65). The program staff was asked to look at these dimensions and offer interpretations of what the dimensions might represent. The participants suggested that the two dimensions represent the main strategies they use.

Outcomes. The "outcomes" columns were described last. First, the program staff examined and discussed the cluster maps with regard to the outcomes they could expect based on services they provided. Next, the staff looked at how the logic model showed the linkage between conditions, interventions, and expected outcomes. During this process the researchers suggested that staff review the four-cluster solution map to relate services provided to potential outcomes. The first category of services, "preparation" for the assessment, appeared to lead to better understanding the multiple problems of children referred to FITP, which is an expected short-term outcome. Similarly, the "assessment" activities were expected to result in identification of the problem or a child's diagnosis. Activities that involved the contribution of all team members ("team process"), including parents and educators, were thought to identify co-existing problems. Finally, "recommendations" made by the program staff were expected to provide the family and teachers with specific knowledge to help them address the problems. The expected long-term outcomes included family and educator empowerment, conflict resolution between the child and the environment, and reduced fragmentation of treatment approaches.

\section{The Staff's Perception of Importance and Effectiveness of Services}

As Bickman et al. (1992) noted, once components and the activities associated with them are explicated, the next step is to assign value to each activity so that evaluators can assess service quality, that is, importance and, effectiveness. To examine the staff's perception of importance and effectiveness of services, clusters with layers were generated where the number of layers represented the level of importance or effectiveness. Figure 3 shows the cluster rating map where the layers of each cluster depict the average importance rating, with more layers equivalent to higher importance. Figure 4 shows the cluster rating map where the layers depict 


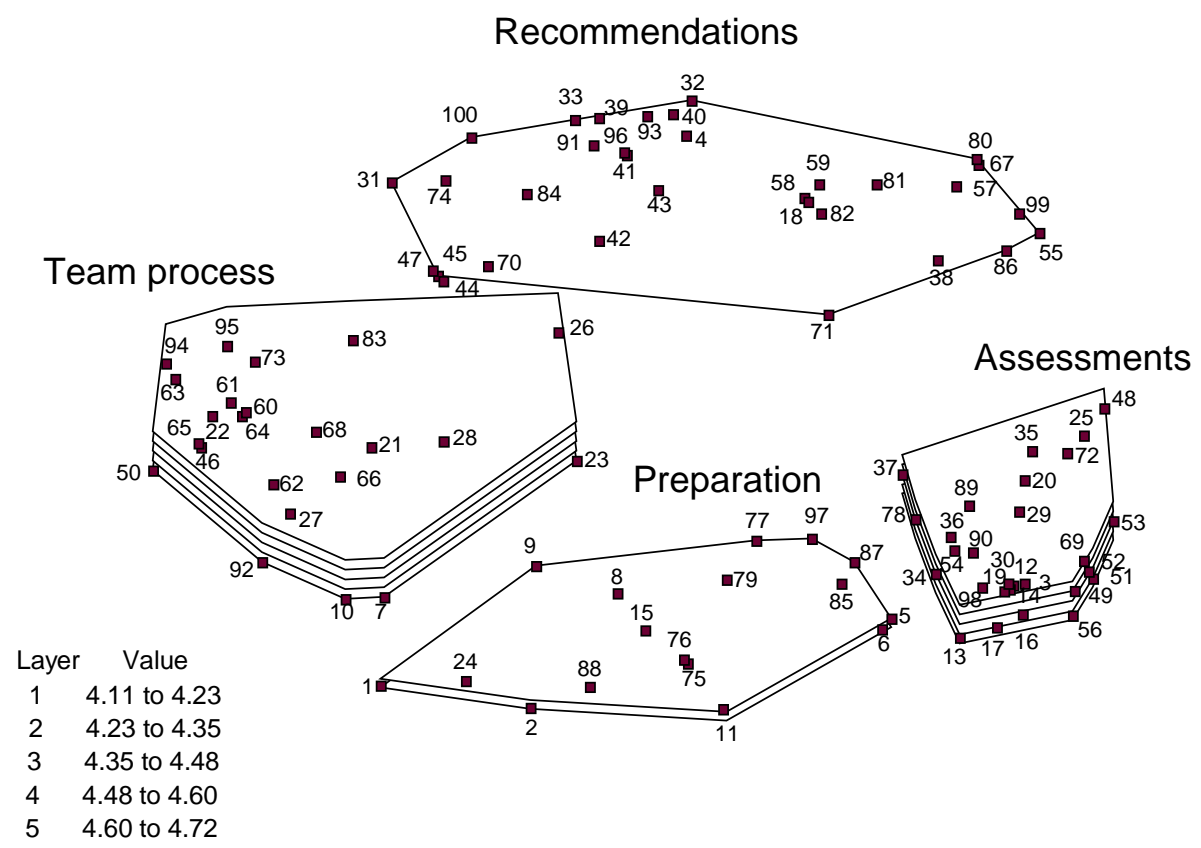

Figure 4. Four-cluster solution rating map. The perceived effectiveness of service activities.

the average effectiveness rating, with more layers equivalent to higher effectiveness. ${ }^{3}$ The number of layers indicates the average importance or effectiveness rating across all items in the cluster, which ranged between 4 and 5 points as shown in the legend. Effectiveness of services as perceived by the program staff showed strengths in the areas of assessments and team process and comparative weakness in the areas of preparatory activities and recommendations (see Fig. 4). The Team Process cluster was perceived by the staff as the most effective as well as the most important (see Figs. 3 and 4). However, the recommendations cluster, which was perceived as being relatively important, was rated comparatively low in effectiveness. It should also be noted that importance and effectiveness were rated relatively high for all clusters, i.e., averages were above 4 on a 5-point scale.

\section{Theory of Change}

The FITP staff reported using a developmental-holistic approach as the major principle of their theory of change. The underlying assumption of this approach is that a child is an integral part of his/her environment and should be viewed within the dynamic systems of the family, school, community, and culture, as well as viewed in the context of his/her developmental stage. In order to articulate the theory of change, the causal relationships between three key elements in the logic model were examined. These key elements were the population served, the strategies used including services, and the intended outcomes (Hernandez \& Hodges, 2001). The logic model depicts the FITP target population as children with multiple needs. The FITP services believed to be critical to producing a positive change consist of various perspectives, disciplines, and resources needed to achieve comprehensive understanding of a 


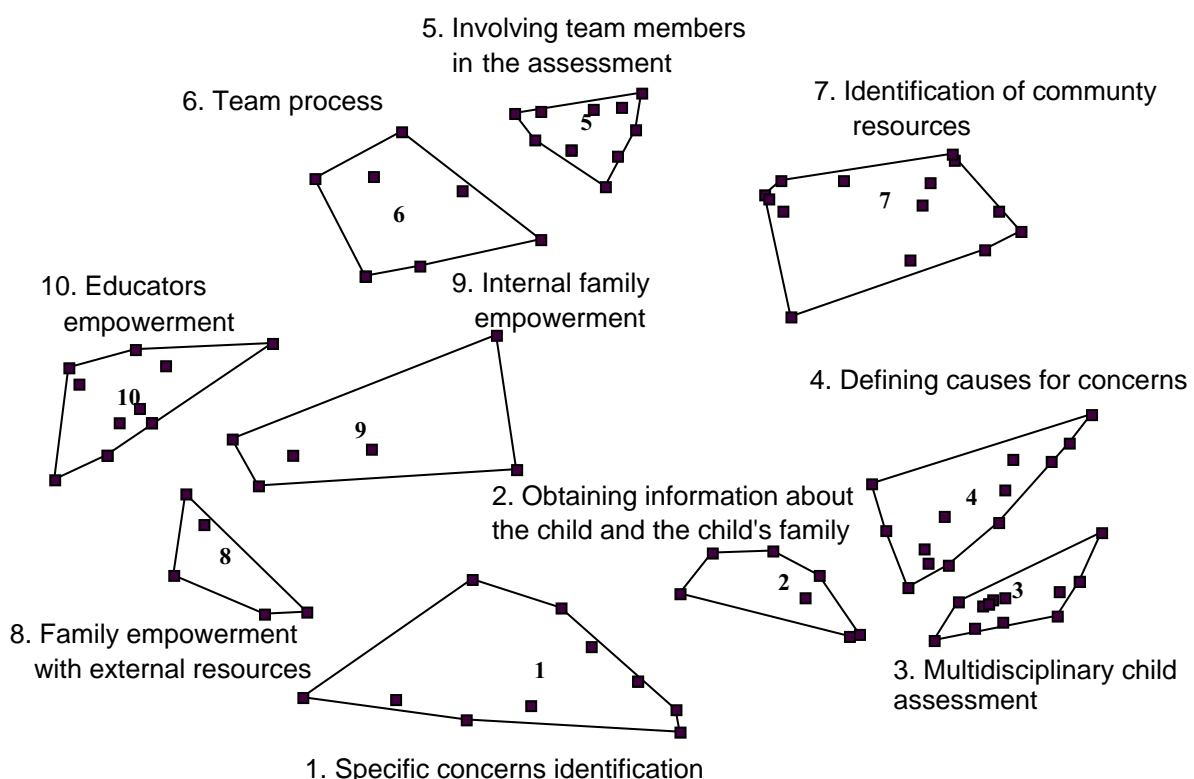

Figure 5. Ten-cluster solution cluster map. Concepts that represent FITP theoretical approach.

child's difficulties. Strategies to carry out the theory of change include collaboration between representatives of different fields and different levels of intervention, and these strategies are believed to enhance service effectiveness as indicated by the staff rating of effectiveness. The services and strategies identified in the logic model were thought to be those that lead to the desired outcomes (see Fig. 1).

As Hernandez and Hodges (2001) indicated, a theory of change can also be defined as the belief that implementers have about how and why a program works. Moreover, Leeuw (2003) noted that "mental models" or "cognitive maps" of members of the organizations are important for predicting the anticipated impact of their policies and programs. Therefore, concept maps obtained by concept mapping were also examined in order to assess underlying assumptions or implicit concepts built in the FITP theoretical approach. As Lipsey and Pollard (1989) noted, the advantage of this technique is that it approaches the question of program theory in small steps that do not require respondents to articulate a full causation mechanism in general or abstract terms. Several cluster maps were examined in order to arrive at meaningful concepts involved in the FITP theory of change. For this purpose a ten-cluster solution rather than four-cluster solution was chosen in order to better describe the major theoretical concepts to be included in the theory of change. This map (see Fig. 5) portrays the program model as envisioned by the program staff. Each cluster represents a concept with statements providing the operational definition of this concept. The following key concepts comprise the FITP theoretical approach: (a) specific concerns identification, (b) obtaining information about the child and the child's family, (c) multidisciplinary child assessment, (d) defining causes for concerns, (e) involving team members in the assessment, (f) team process, (g) identification of community resources, (h) family empowerment with external resources, (i) internal family empowerment, and (j) educator empowerment. 


\section{DISCUSSION}

Using the FITP program as an example, we have attempted here to demonstrate the utilization of a concept mapping procedure in developing the components of a logic model and in articulating a theory of change. Specifically, concept mapping was used to identify the target population, program services, program structure, and program strategies, as well as to elicit "mental models" of the program. When developing the logic model, concept mapping served a number of beneficial functions. First, we believe that the use of concept mapping allowed for easier and more accurate identification of the program details essential for logic models (Stinchcomb, 2001), because concept maps visually illustrated the program scope of services, the relationships among them, and the program structure. The concept maps and the statements generated as a result of the concept mapping were tools that identify program services. Second, because concept maps presented a visual representation of program elements, their examination facilitated the discussion about the "activities" and "categories of services" components of the logic model. As Shern et al. (1995) noted, concept mapping provides a structured analytic process for program developers, staff, and others to identify the key aspects of a program and graphically portray the relationships among the elements. Third, the brainstorming and sorting stages of the concept mapping procedure enabled the participants to come to a mutual understanding about program services and structure, which in turn enhanced the development of a more complete logic model. After completing the concept mapping process, program staff reported that they had a clearer vision of their program. As Adler (2002) noted, logic models and, therefore, evaluation and evaluation planning benefit from an "inclusionary" approach in which the program or agency staff becomes a part of an assessment process. Fourth, concept mapping efficiently handled the seven participants and various (even contradictory) ideas they had about their program, so that everybody could give input and all agree on the essence of their program. Fifth, as a quantitative technique, concept mapping produced a conceptual organization of complex information (Johnsen, Biegel, \& Shafran, 2000), which is essential for quality and the content of the program logic model. Sixth, it allowed the participants to meaningfully interpret and utilize qualitative information and, therefore, better control the content that later was utilized for the logic model development. Overall, concept maps were used as a guide and facilitated the discussion of the logic model with the program staff. In addition, concept mapping helped to identify the strengths and weaknesses of the program through importance and effectiveness ratings. As Savas et al. (1998) noted, appropriateness and effectiveness of services are two important quality domains that are necessary to review.

Concept mapping also appears to be a good tool for organizing complex ideas about a program and the way a program works. From this perspective, concept mapping helps reveal the underlying assumptions that guide service delivery and therefore helps articulate the theory of change. However, only a logic model shows linkages between the program components, thus revealing how the program works to address needs of a target population.

A more detailed program logic model could also show program inputs and program context. We presented a version of a logic model that allows for articulation of the theory of change at a macro level. Therefore, this logic model illustrated only the elements that are essential for the articulation of the theory of change, which include the target population, activities, strategies, and the expected outcomes (Hernandez, 2000). 


\section{Limitations of the Study and Lessons Learned}

Limitations of the study should be noted. First, as it was mentioned, the program model was more complex than the conceptual illustration of Figure 1. Specifically, inputs and context of the program were not illustrated in the program model given here. Including these components would help to assess whether in fact the program services will cause the expected outcomes.

Second, the focus statement used in this study prompted the participants to describe the program services, and therefore, the resulted maps illustrated the relationships among statements that described program services and categories of services. It would be interesting to use another focus statement asking the participants about program outcomes and use the resulting concept maps for the outcomes component of the logic model. Future studies should attempt to obtain both "activities" and "outcomes" maps and examine the links and relationship between them.

Third, only staff members were the participants in this study. It would be useful to have family members rate the services on importance and effectiveness and compare their perception with the perception of the FITP staff. Naturally, family members might have different ideas about what services are most important and effective. This information would be helpful in setting priorities for program planning and modification. In addition, the areas identified as important by the family members could guide future evaluation of the program.

\section{Conclusions}

This paper presents a strategy for developing components of a logic model and the theory of change using a concept mapping technique. The applicability of multidimensional scaling has been illustrated in the evaluation of social services for children and adolescents (Hare, 1999). Hierarchical cluster analysis has been useful in identifying types of mental health services utilization (Lambert et al., 1998). Concept mapping has been used in a variety of projects (Johnsen et al., 2000), including program planning (Trochim, 1989b) and program fidelity (Shern et al., 1995). Logic models also have been used in assessment of program performance (McLaughlin \& Jordan, 1999), linking accountability and program planning (Hernandez, 2000; Julian, Jones, \& Deyo, 1995; Savas et al., 1998), and for articulating a theory of change (Hernandez, 2000; Hernandez \& Hodges, 2001). Unique to the present study is the use of concept mapping for developing the components of a logic model and articulation the theory of change. The results of the study indicated how the linkages between the program components should theoretically work to deal with children who have multiple problems. The program model will in turn assist in designing future evaluation and guide the evaluators through a selection of key activities and outcomes.

\section{Notes}

1. The real name of the program was changed at the request of the Institutional Review Board because of confidentiality issues.

2. A three-dimensional solution was examined and was rejected in favor of a two-dimensional solution. Though the stress value improved with the three-dimensional solution, the two-dimensional solution was chosen for its ease of interpretability.

3. Note that the average represented by the layers in the map is actually a double averaging-across all of the participants and across all of the factors in each cluster. Consequently, even slight differences 
in averages between clusters are likely to be meaningfully interpretable (Trochim, Stillman, Clark, \& Schmitt, 2003).

\section{REFERENCES}

Adler, M. A. (2002). The utility of modeling in evaluation planning: The case of the coordination of domestic violence services in Maryland. Evaluation and Program Planning, 25, 203-213.

Beck, S. A., Meadowcroft, P., Mason, M., \& Kiely, E. S. (1998). Multiagency outcome evaluation of children's services: A case study. Journal of Behavioral Health Service and Research, 25, 163-176.

Bickman, L., Heflinger, C. A., Pion, G., \& Behar, L. (1992). Evaluation planning for an innovative children's mental health system. Clinical Psychology Review, 12, 853-865.

Carroll, J. D., \& Chang, J. J. (1970). Analysis of individual differences in multidimensional scaling via $\mathrm{N}$-way generalization of "Eckart-Young" decomposition. Psychometrika, 35, 283-319.

Chen, H. T. (1990). Theory-driven evaluations. Newbury Park: Sage.

Chen, H. T., \& Rossi, P. H. (1983). Evaluating with sense: The theory-driven approach. Evaluation Review, 7, 283-302.

Friedman, R. M. (1997). Evaluating mental health services: How do programs for children "work" in the real world? Thousand Oaks, CA: Sage.

Hare, F. G. (1999). Applications of multidimensional similarity scaling (MDS) in Evaluation Research. Children and Youth Services Review, 21, 147-166.

Hernandez, M. (2000). Using logic models and program theory to build outcome accountability. Education and Treatment of Children, 23, 24-40.

Hernandez, M., \& Hodges, S. P. (2001). Theory-based accountability. In M. Hernandez \& S. Hodges (Eds.), Developing outcome strategies in children's mental health. Baltimore, MD: Paul H. Brookes.

Hernandez, M., Hodges, S. P., \& Cascardi, M. (1998). The ecology of outcomes: System accountability in children's mental health. The Journal of Behavioral Health Services and Research, 25, 136-150.

Hodges, S. P., \& Hernandez, M. (1999). How organizational culture influences outcome information utilization. Evaluation and Program Planning, 22, 183-197.

Johnsen, J. A., Biegel, D. E., \& Shafran, R. (2000). Concept mapping in mental health: Uses and adaptations. Evaluation and Program Planning, 23, 67-75.

Julian, D. A. (1997). The utilization of the logic model as a system level planning and evaluation device. Evaluation and Program Planning, 20, 251-257.

Julian, D. A., Jones, A., \& Deyo, D. (1995). Open systems evaluation and the logic model: Program planning and evaluation tools. Evaluation and Program Planning, 18, 333-341.

Kruskal, J. B., \& Wish, M. (1978). Multidimensional scaling. Beverly Hills, CA: Sage.

Lambert, E. W., Brannan, A. M., Breda, C., Heflinger, C. A., \& Bickman, L. (1998). Common patterns of service use in children's mental health. Evaluation and Program Planning, 21, 47-57.

Leeuw, F. L. (2003). Reconstructing program theories: Methods available and problems to be solved. American Journal of Evaluation, 24, 5-20.

Lipsey, M. W., \& Pollard, J. A. (1989). Driving toward theory in program evaluation: More models to choose from. Evaluation and Program Planning, 12, 317-322.

McLaughlin, J. A., \& Jordan, G. B. (1999). Logic models: A tool for telling your program's performance story. Evaluation and Program Planning, 22, 65-72.

Mowbray, C. T., Holter, M. C., Teague, G. B., \& Bybee, D. (2003). Fidelity criteria: Development, measurement, and validation. American Journal of Evaluation, 24, 315-340.

Pumariega, A. J. (1996). Culturally competent outcome evaluation in systems of care for children's mental health. Journal of Child and Family Studies, 5, 389-393.

Rosenberg, S., Nelson, C., \& Vivekananthan, P. S. (1968). A multidimensional approach to the structure of personality impressions. Personality and Social Psychology, 9, 283-294.

Rossi, P. H., \& Freeman, H. E. (1993). Evaluation: A systematic approach. Beverly Hills, CA: Sage. 
Savas, S. A., Fleming, W. M., \& Bolig, E. E. (1998). Program specification: A precursor to program monitoring and quality improvement. A case study from Boysville of Michigan. The Journal of Behavioral Health Services \& Research, 25, 208-216.

Shern, D., Trochim, W. M. K., \& LaComb, C. A. (1995). The use of concept mapping for assessing fidelity of model transfer: An example from psychiatric rehabilitation. Evaluation and Program Planning, 18, 143-153.

Solomon, B. (2002). Accountability in public child welfare: Linking program theory, program specification and program evaluation. Children and Youth Services Review, 24, 385-407.

Stinchcomb, J. B. (2001). Using logic modeling to focus evaluation efforts: Translating operational theories into practical measures. Journal of Offender Rehabilitation, 33, 47-66.

Trochim, W. M. (1989a). An introduction to concept mapping for planning and evaluation. Evaluation and Program Planning, 12, 1-16.

Trochim, W. M. (1989b). Concept mapping: Soft science or hard art? Evaluation and Program Planning, $12,87-110$.

Trochim, W. M. (1993). The concept system. Ithaca, NY: Concept Systems.

Trochim, W. M., Stillman, F. A., Clark, P. I., \& Schmitt, C. L. (2003). Development of a model of the tobacco industry's interference with tobacco control programmes. Tobacco Control, 12, 140-147.

Unrau, Y. A. (2001). Using client exit interviews to illuminate outcomes in program logic models: A case example. Evaluation and Program Planning, 24, 353-361.

Ward, J. H. (1963). Hierarchical grouping to optimize an objective function. Journal of the American Statistical Association, 58, 33-44.

Weiss, C. H. (1997). How can theory-based evaluation make greater headway? Evaluation Review, 21, 501-524. 